ORIGINAL RESEARCH ARTICLE

\title{
The Relationship between Facility-Based Delivery and Infant Immunization in sub-Saharan Africa
}

\author{
Cheryl A. Moyer ${ }^{1,2,3}$, Dana Benyas ${ }^{1}$ and Sarah Rominski ${ }^{1}$ \\ Global REACH, University of Michigan Medical School ${ }^{1}$; Department of Learning Health Sciences, University of Michigan \\ Medical School ${ }^{2}$; Department of Obstetrics and Gynecology, University of Michigan Medical School ${ }^{3}$
}

*For Correspondence: Email: camoyer@umich.edu; Phone: +1-734-615-2838

\begin{abstract}
This study explored the relationship between facility-based delivery and infant immunizations in sub-Saharan Africa, controlling for economic development indicators. Publically available data were collected and imported into Stata 11.0 for descriptive, correlation, and regression analyses. Facility delivery was significantly associated with full vaccination and BCG immunization in children aged 12-23 months. Facility delivery was associated with full vaccination $(\mathrm{p}<.019)$, even after controlling for antenatal care usage, Gross National Income per capita, percent of the country's population residing in an urban setting, and percent of the population with at least a secondary education $(\beta: 0.45(95 \% \mathrm{CI}: 0.08-0.81))$. The relationship between facility delivery and immunization is significant, and robust enough to remain after controlling for economic and social indicators linked to both. These results suggest the benefits of facility delivery transcend the immediate survival benefit for mothers and their babies, and may serve as a gateway to further interactions with the healthcare system. (Afr. J Reprod Health 2016; 20[2]: 27-33).
\end{abstract}

Keywords: institutional delivery; skilled birth attendance; infant immunizations; Africa; developing countries.

\section{Résumé}

Cette étude a exploré la relation entre l'accouchement dans les établissements de santé et les immunisations en Afrique subsaharienne, le contrôle des indicateurs de développement économique. Les données qui sont publiquement disponibles ont été recueillies et importées dans Stata 11.0 pour des analyses descriptive, de la corrélation et de la régression. L'accouchement dans les établissements de santé était significativement associé à la vaccination complète et la vaccination par le BCG chez les enfants âgés de 12-23 mois. L'accouchement dans les établissements de santé a été associée à la vaccination complète (p <0,019), même après avoir contrôlé l'utilisation des soins prénatals, le revenu national brut par habitant, pourcent de la population du pays vivant en milieu urbain, et pourcent de la population avec au moins une éducation secondaire ( $\beta$ : 0,45 (IC à $95 \%$ : 0,08 à 0,81$)$ ). La relation entre la prestation de service et la vaccination est importante, et suffisamment robuste pour rester après contrôle des indicateurs économiques et sociaux liés à tous les deux. Ces résultats suggèrent que les avantages de l'accouchement dans les établissements de santé dépassent l'avantage immédiat de survie pour les mères et leurs bébés, et peuvent servir de passerelle vers d'autres interactions avec le système de soins de santé. (Afr. J Reprod Health 2016; 20[2]: 27-33).

Mots-clés: accouchement institutionnel; accoucheuses qualifiées; vaccinations de l'enfant; Afrique; pays en voie de développement.

\section{Introduction}

Facility-Based Delivery (FBD) has been linked to improved outcomes for both mothers and babies in the developing world in the period immediately surrounding birth ${ }^{1-4}$. At the same time, infant immunizations are a leading strategy to reduce infant and child mortality ${ }^{5}$. By some estimates, vaccines prevent 2-3 million deaths each year. However, even with huge successes in developing vaccines to prevent diseases which kill the most children, over 10 million children in low- and middle-income die before their fifth birthdays every year. While global immunization coverage for diphtheria-tetanus-pertussis-3 (DTP-3) has reached close to $80 \%$ worldwide in the past decade, in sub-Saharan Africa this rate is only $69 \%$. Both facility delivery and immunization require engagement with the healthcare system, yet very little research has explored the 
relationship between these two discrete events. In one previous study in Ethiopia, facility delivery was linked to an increased likelihood of childhood immunization, even when factors associated with both facility delivery and immunization were controlled $^{8}$. Other studies have shown facility delivery to be one of many factors associated with full vaccination ${ }^{9}$. However, both facility delivery and immunization status are sensitive to underlying national factors, such as the wealth of the country, the average level of education, or the percent of the population living in close proximity to high-quality healthcare. Research to date has not answered the question of whether a country's economic development indicators are a better predictor of immunization status than facility delivery.

This study sought to look beyond singlecountry studies and determine if an association between facility delivery and infant immunizations held true when looking across all of sub-Saharan Africa and when controlling for economic development indicators. The following research questions guided this study: 1) Is facility-based delivery associated with infant immunizations in sub-Saharan Africa? 2) When factors that are associated with both facility delivery and immunizations are held constant, does the relationship between facility delivery and infant immunizations hold?

\section{Materials and Methods}

Publically available, country-specific data from the World Health Organization, the United Nations, the World Bank, Measure DHS's Demographic and Health Surveys, and the International Monetary Fund were collected for all nations of sub-Saharan Africa and entered into an Excel spreadsheet ${ }^{10-11}$. Datasets were accessed in 2014 but reflected data from 2006-2012.

National indicators collected included: percentage of births conducted in a facility, percentage of pregnant women obtaining any Antenatal Care (ANC), percentage of pregnant women receiving 4 or more ANC visits, percent of the population living in an urban area, Gross National Income (GNI) per capita, percent of children aged 12-23 months who had received any of the following vaccinations: BCG (Bacille Calmette Guerin, to prevent tuberculosis), hepatitis B, diphtheria/pertussis, Haemophilus influenza B, measles, and polio; and percent of children aged 12-23 months who had received at least one dose of all of the listed vaccinations (defined for this study as "fully vaccinated"). Demographic variables were chosen due to their established relationship to both facility-based delivery $^{12}$ and infant immunization status ${ }^{13-14}$. The outcome variable was the continuous variable, national percentage of births conducted in a facility.

Data were imported into Stata 11.0 (College Station, TX) for analysis. Bivariate analyses were conducted using Pearson's R to calculate correlation coefficients for facility delivery and immunization variables, as well as between the variables expected to be associated with both facility delivery and immunization (any ANC, 4+ ANC visits, GNI per capita, percent of the population with a secondary education, and percent of the population living in an urban area).

Multivariate linear regression analyses were conducted to determine the relationship between facility-based delivery and immunization status. Given the exploratory nature of the analysis, a pvalue of 0.10 was considered significant.

This research was conducted with publically available, aggregated, anonymous, secondary data, thus ethical approval was waived by the University of Michigan Institutional Review Board.

\section{Results}

Data were available on maternal and infant variables for 50 countries in sub-Saharan Africa (See Table 1). However, key indicators were missing for Cameroon, Central African Republic, Comoros, Mauritania, Seychelles, Sierra Leone, Timor-Leste, yielding a final sample of 43 nations.

In bivariate analysis, the country-wide percentage of women obtaining facility-based delivery was significantly associated with the national percent of children aged 12-23 months who were fully vaccinated (Pearson $\mathrm{R}=0.32$, $\mathrm{p}=.060)$ and who received $\mathrm{BCG}$ immunization (Pearson $\mathrm{R}=0.44, \mathrm{p}=.002$ ); countries with higher 
Table 1: Countries Included, and National Percents of Facility Delivery and Infant Vaccination ${ }^{10-11}$

\begin{tabular}{|c|c|c|c|}
\hline Country & $\begin{array}{l}\text { Percent of women } \\
\text { receiving any } \\
\text { antenatal care (ANC) }\end{array}$ & $\begin{array}{l}\text { Percent of Deliveries } \\
\text { occurring in Facility }\end{array}$ & $\begin{array}{l}\text { Percent of children } \\
12-23 \text { months fully } \\
\text { vaccinated }\end{array}$ \\
\hline Angola & 67.6 & 46 & - \\
\hline Benin & 85.8 & 78 & 47.1 \\
\hline Botswana & 93.6 & 94 & 65.7 \\
\hline Burkina Faso & 94.9 & 51 & 81.3 \\
\hline Burundi & 98.9 & 60 & 83 \\
\hline Cameroon & 84.7 & 61 & 53.2 \\
\hline Cape Verde & 90.9 & 78 & - \\
\hline Central African Republic & 54.6 & 56 & 36.6 \\
\hline Chad & 42.6 & 16 & 11.3 \\
\hline Comoros & 92.1 & - & 54.5 \\
\hline Congo & 89.7 & 82 & 52.1 \\
\hline Cote d'Ivoire & 88.9 & 54 & 50.7 \\
\hline Democratic Republic of Congo & 88.8 & 74 & 30.6 \\
\hline Djibouti & 81.0 & - & - \\
\hline Equatorial Guinea & 91.0 & - & - \\
\hline Eritrea & - & 26 & 75.9 \\
\hline Ethiopia & 33.9 & 5 & 24.3 \\
\hline Gabon & 94.7 & 85 & 14.6 \\
\hline Gambia & 86.2 & 55 & - \\
\hline Ghana & 96.4 & 57 & 14.6 \\
\hline Guinea & 85.2 & 39 & 37.2 \\
\hline Guinea-Bissau & 93.0 & 39 & 37.2 \\
\hline Kenya & 91.5 & 42 & - \\
\hline Lesotho & 91.8 & 43 & 68.3 \\
\hline Liberia & 95.9 & 59 & 61.7 \\
\hline Madagascar & 86.3 & 37 & - \\
\hline Malawi & 94.7 & 35 & 61.6 \\
\hline Mali & 70.4 & 54 & 80.9 \\
\hline Mauritania & 72.3 & 45 & 48.2 \\
\hline Mauritius & - & - & 31.9 \\
\hline Mozambique & 90.6 & 98 & - \\
\hline Namibia & 94.6 & 58 & 63.3 \\
\hline Niger & 46.1 & 81 & 68.7 \\
\hline Nigeria & 52.9 & 17 & 29 \\
\hline Rwanda & 98.0 & 35 & 22.7 \\
\hline Sao Tome and Principe & 97.5 & 69 & 90.1 \\
\hline Senegal & 93.3 & 79 & 76.6 \\
\hline Seychelles & - & 62 & 62.8 \\
\hline Sierra Leone & 91.1 & - & - \\
\hline Somalia & 22.0 & 25 & 39.8 \\
\hline South Africa & - & - & - \\
\hline South Sudan & 68.9 & 89 & 63.4 \\
\hline Sudan & 40.3 & - & 51.6 \\
\hline Swaziland & 96.8 & 19 & - \\
\hline Tanzania & 87.8 & 80 & 81.7 \\
\hline Timor-Leste & 84.4 & 50 & 75.2 \\
\hline Togo & 50.7 & 67 & 30.8 \\
\hline Uganda & 94.9 & 22 & - \\
\hline Zambia & 93.7 & 41 & 51.6 \\
\hline Zimbabwe & 89.8 & - & - \\
\hline
\end{tabular}


Table 2: Bivariate Analyses Examining the Relationship between Facility Delivery, Infant Vaccination, and other Key Variables

\begin{tabular}{|c|c|c|c|}
\hline & Mean (SD, Min-Max) & $\begin{array}{l}\text { Pearson's R } \\
\text { vs. } \\
\text { facility-based delivery }\end{array}$ & P Value \\
\hline $\begin{array}{l}\text { Facility-based delivery } \\
\text { Immunization Variables }\end{array}$ & $54.3(22.7,5.0-98.0)$ & N/A & N/A \\
\hline BCG & $87.4(13.8,29.0-99.0)$ & 0.449 & 0.002 \\
\hline Hepatitis B & $78.3(16.0,33.0-99.0)$ & 0.189 & 0.235 \\
\hline DPT & $78.3(16.0,33.0-99.0)$ & 0.189 & 0.235 \\
\hline Influenza B & $79.8(14.5,45.0-99.0)$ & 0.049 & 0.766 \\
\hline Measles & $77.5(15.7,46.0-99.0)$ & 0.238 & 0.134 \\
\hline Polio & $79.2(16.0,39.0-99.0)$ & 0.133 & 0.406 \\
\hline $\begin{array}{l}\text { "Fully vaccinated" (at least } \\
\text { one dose of all of the above) }\end{array}$ & $53.3(21.4,11.3-90.1)$ & 0.321 & 0.060 \\
\hline Other key variables & & & \\
\hline $\begin{array}{l}\text { Gross national income per } \\
\text { capita (in US dollars) }\end{array}$ & $\$ 1793.70(2,757,160-14,680)$ & 0.622 & $<0.0001$ \\
\hline $\begin{array}{l}\text { Percent of the population } \\
\text { with at least a secondary } \\
\text { education }\end{array}$ & $29.2(19.5,6.1-69.7)$ & 0.543 & 0.0005 \\
\hline $\begin{array}{l}\text { Percent of the population } \\
\text { living in an urban area }\end{array}$ & $38.9(16.6,11.0-86.0)$ & 0.471 & 0.0022 \\
\hline $\begin{array}{l}\text { Percent of women receiving } \\
\text { any ANC }\end{array}$ & $80.8(19.5,22-98.9)$ & 0.587 & 0.0001 \\
\hline $\begin{array}{l}\text { Percent of women receiving } \\
4+\text { ANC visits }\end{array}$ & $50.3(19.9,6.3-86.6)$ & 0.625 & 0.0001 \\
\hline
\end{tabular}

Table 3: Multivariate Regression Analyses

\begin{tabular}{|c|c|c|c|c|}
\hline Variable & $\begin{array}{l}\text { Model 1: } \\
\text { BCG Vaccination } \\
\text { Adjusted } \mathbf{R}^{2}: 0.36 \\
\text { Coef. }(95 \% \text { CI }) \\
\end{array}$ & P value & $\begin{array}{l}\text { Model 2: } \\
\text { FBD + ANC; Full Vaccination } \\
\text { Adjusted } \mathbf{R}^{2}: 0.67 \\
\text { Coef. }(95 \% \text { CI })\end{array}$ & P value \\
\hline Facility delivery & $0.18(-0.005-0.49)$ & 0.167 & $0.45(0.08-0.81)$ & 0.019 \\
\hline$\%$ w/any ANC visits & $0.24(0.16-0.90)$ & 0.055 & $0.56(0.21-0.92)$ & 0.003 \\
\hline GNI per capita & $-0.0004(-0.003-0.003)$ & 0.767 & $0.001(-0.002-0.005)$ & 0.494 \\
\hline$\%$ urban & $-0.009(-0.31-0.30)$ & 0.952 & $-0.95(-1.4--0.51)$ & $<0.001$ \\
\hline $\begin{array}{l}\% \text { with secondary } \\
\text { education }\end{array}$ & $-0.004(-0.23-0.22)$ & 0.969 & $-0.192(-0.49-0.12)$ & 0.196 \\
\hline Constant & $58.2(38.9-77.3)$ & $<0.001$ & $18.2(-8.2-44.6)$ & 0.167 \\
\hline
\end{tabular}

rates of facility-based delivery also had higher rates of full vaccination and BCG vaccination. This relationship did not extend to other immunizations. (See Table 2.)

As expected, the proportion of births conducted in a facility were also significantly associated with Gross National Income per capital, percent of the population with at least a secondary education, percent of the population living in an urban area, percent of pregnant women receiving any ANC, and percent of pregnant women receiving 4 or more ANC visits. (See Table 2.). Given the overlap between the two ANC variables, only "percent receiving any ANC visits" was chosen for inclusion in multivariate modeling. Urban status, percent receiving any ANC, and 4 or more ANC visits were also associated with BCG and full immunization status.

Table 3 illustrates the multivariate linear regression models for both BCG coverage and full vaccination status, controlling for national statistics on: percent of women receiving any ANC visits, GNI per capita, percent of the population living in an urban area, and percent of the adult population with a secondary education. Model 1 shows that facility delivery no longer remains associated with $\mathrm{BCG}$ vaccination once other key variables are included in the model. 
However, facility delivery remains significantly associated with full vaccination, even after controlling for Gross National Income, percent of the population living in an urban area, percent of the population with at least a secondary education, and percent of pregnant women receiving any antenatal care. Facility delivery confers a $45 \%$ increased likelihood of full infant vaccination. Attending any antenatal care confers a 56\% increased likelihood of full vaccination.

\section{Discussion}

This study finds that having been born in a facility is associated with increased likelihood of full immunization by the time these children are 12 to 23-months old. This relationship remains robust even after controlling for economic and social indicators that are likely linked to both. These results suggest that the benefits of facility delivery go beyond the immediate survival benefit for mothers and their babies, and may serve as a gateway to further interactions with the healthcare system. Given the enormous health benefit that immunizations provide, and the large number of vaccine-preventable deaths still occurring in under-fives in sub-Saharan Africa, increasing the rates of facility-based delivery could be one strategy to integrate families into the healthcare system to ensure full vaccination coverage of children.

This research, which includes data from 43 nations in sub-Saharan Africa, supports previous work conducted by the lead author in Ethiopia exploring the relationship between immunization and facility delivery. In that single-country study using national Demographic and Health Surveillance data, facility delivery was significantly associated with increased likelihood of DPT-HepB-Hib, polio, and measles vaccination, as well as being fully immunized. Facility delivery was the single strongest factor in a multivariate model predicting full immunization ${ }^{8}$.

Other research within Ethiopia indicates that being born in a health facility doubles the odds of complete immunization, along with several other factors in a multivariate regression model ${ }^{9}$. Antenatal care follow-up, mothers' knowledge about the age at which vaccination begins, and knowledge of when vaccinations are complete were also significantly associated with complete immunization. Notably, area of residence and women's socio-demographic characteristics were not significantly associated with full immunization? .

In a study conducted in Burkina Faso, the authors conclude that instead of focusing on women's education or other socio-demographic factors to target immunization campaigns, "Continuity from prenatal care to institutional delivery creates a loyalty to healthcare services and is the most significant and stable explanatory factor associated with complete vaccination of children ${ }^{15}$." This comment is especially prescient, given our finding that one of the only factors in addition to facility delivery that was significantly associated with full vaccination was antenatal care attendance. Women who seek care in a facility, first for antenatal care, and then for delivery, are engaging with the healthcare system in a fundamentally different way than women who opt out of ANC and deliver at home. While not attending ANC and delivering at home are associated with well-known short term negative consequences such as pregnancy and delivery complications, this research suggests that there may be longer term negative consequences as well.

One strength of this study is that it is the only research of which we are aware that directly addresses the relationship between place of delivery and immunization status in sub-Saharan Africa as a region. In addition, data was pulled from established, well-respected sources, and 43 countries in sub-Saharan Africa were represented in these analyses. Thus, this research provides a broad assessment of the situation, beyond previously conducted research that was limited to a single country.

However, this study is not without limitations. First, this study relies upon nationlevel data, rather than individual-level data. Thus conclusions must be drawn carefully. Unlike our previous work in Ethiopia, we cannot conclude from this research that women who deliver in a facility are more likely to have fully immunized children: this analysis instead demonstrates that 
countries with high proportions of facility based delivery are also more likely to have high rates of full vaccination for children aged 12-23 months, and this association is not explained by social development indicators like Gross National Income, percent of the population with a secondary education, or percent of the population living in an urban area. Further research that utilizes individual-level data across sub-Saharan Africa is warranted.

Another limitation is that despite data coming from globally well-respected sources, it is possible that data were not accurate. Collecting accurate data about maternal and child indicators in developing country settings is extremely challenging even under ideal circumstances, and many of the countries included in this analysis have undergone political and social upheavals that may render the statistics reported to the national and international authorities somewhat suspect. Data regarding immunizations is especially problematic. It relies upon a mother retaining her baby's immunization card - assuming the immunization card was completed accurately - or maternal recall. Neither option is ideal. However, it is likely to lead to underestimates in vaccination rates, rather than overestimates, which potentially makes our estimated relationships conservative and not upwardly biased. Finally, national-level data may mask huge within-country variations in rates of both facility delivery and immunizations. Nonetheless, these are the best data available at present.

\section{Conclusion}

In conclusion, antenatal care and facility delivery need to be viewed as potential entry points into the healthcare system, during which women can begin to develop a longitudinal relationship with the healthcare system. Thus ANC and facility delivery have the potential to not only reduce maternal mortality and early neonatal mortality associated with delivery-related events, but the exposure to facilities during that process can influence maternal behavior in the months and years following delivery ${ }^{8}$. This is an important perspective for providers to understand and embrace: Providers have a direct role in encouraging women's ongoing engagement with the formal healthcare system. In addition, beyond general measures of development such as population-level education and wealth, engagement with the healthcare system is highly associated with immunization coverage. Such a finding not only reiterates the importance of healthcare providers and a healthcare system designed to promote long-term engagement, but it also suggests that nations and regions need not be wealthy and well-educated before they can make significant gains in immunization rates.

\section{Conflict of Interest}

The authors have no conflict of interest to disclose.

\section{Contribution of Authors}

CAM conceptualized the study, supervised data collection, conducted portions of the data analysis, and wrote initial drafts of the manuscripts. DB collected data, conducted preliminary analysis, and participated in manuscript drafting and revision. SR assisted with the conceptualization of the study, conducted portions of the data analysis and participated in manuscript drafting and revision. All authors reviewed and approved the final version of the manuscript.

\section{References}

1. Moyer CA, Dako-Gyeke P, Adanu RM. Facility-based delivery and maternal and early neonatal mortality in sub-Saharan Africa: A regional review of the literature. Af J Repr Health. 2013A; 17(3): 30-43.

2. Moyer CA, Adanu RM, Engmann CM. The relationship between facility delivery, maternal mortality, and early and late neonatal mortality in sub-Saharan Africa. Int J Gyn Ob. 2013B; 122(3): 263-265.

3. Tura G, Fantahun M, Worku A. The effect of health facility delivery on neonatal mortality: systematic review and meta-analysis. BMC Preg Child. 2013; 13.18

4. Hogan MC, Foreman KJ, Naghavi M, Ahn SY, Wang M, Makela SM, Lopez AD, Lozano R, Murray CJL. Maternal mortality for 181 countries, 1980-2008: a systematic analysis of progress towards Millenium Development Goal 5. The Lancet. 2010; 375(9726): 1609-1623.

5. Andre FE, Booy R, Bock HL, Clemens J, Datta SK, John TJ, Lee BW, Lolekha S, Peltola H, Ruff TA, 
Santosham M, Schmitt HJ. Vaccination greatly reduces disease, disability, death and inequity worldwide. Bull World Health Organ. 2008; 86(2): 81-160.

6. WHO. World Immunization Week 2012, Global Attention on Immunization. Available at: http:// www.who.int/immunization/newsroom/events/imm unization_week/2012/further_information/en/.

7. Arevshatian L, Clements CJ, Lwanga SK, Misore AO, Ndumbe P, et al. (2007) An evaluation of infant immunization in Africa: Is a transformation in progress? Bull World Health Organ. 85: 449-457.

8. Moyer CA, Tadesse L, Fisseha S. The relationship between facility delivery and infant immunization in Ethiopia. Int J Gyn Ob. 2013C; 123(3): 217-20.

9. Etana B, Deressa W. Factors associated with complete immunization coverage in children aged 12-23 months in Ambo Woreda, Central Ethiopia. BMC Pub Health. 2012; 12: 566.

10. UN Data Dataset Explorer. Available at: http://data.un.org/Explorer.aspx?d=WHO.Last accessed on July 15, 2014.

11. Measure DHS. STATCompiler. Available at: http://www.statcompiler.com/ Last accessed on July 15, 2014.

12. Moyer CA and Mustafa A. Drivers and deterrents of facility delivery in sub-Saharan Africa: A systematic review. Reprod Health. 2013D; 10:40. doi:10.1186/1742-4755-10-40.

13. Fernandez RC, Awofeso N, Rammohan A. Determinants of apparent rural-urban differentials in measles vaccination uptake in Indonesia. Rural Remote Health. 2011; 11(3): 1702. Epub 2011 Sept 8.

14. Mathew JL. Inequity in childhood immunization in India: a systematic review. Indian Pediatr. 2012; 49(3): 203-23.

15. Sia D, Fournier P, Kobiane JF, Sondo BK. Rates of coverage and determinants of complete vaccination in children in rural areas of Burkina Faso (19982003). BMC Pub Health. 2009; 9: 416. Doi: $10.1186 / 1471-2458-9-416$ 